\begin{tabular}{ccc}
\hline JOURNAL PHYSICAL \\
HEALTH RECREATION \\
Volume 1 Nomor 1; November 2020
\end{tabular}

\title{
ANALYSIS OF MEN'S VOLLEYBALL VOLLEYBALL UNDERPASS SKILLS IN SETRAK JAYA, SERDANG BEDAGAI REGENCY IN 2019/2020
}

\author{
ANALISIS KETERAMPILAN PASSING BAWAH BOLA VOLI PUTRA \\ SETRAK JAYA KABUPATEN SERDANG BEDAGAI TAHUN 2019/2020
}

\author{
Joyo Andiko ${ }^{1}$, Dewi Maya Sari² \\ Sekolah Tinggi Olahraga dan Kesehatan Bina Guna \\ J1. Alumunium Raya, Sumatera Utara, 20241, Indonesia
}

\begin{abstract}
ABSTRAK
Penelitian ini termasuk penelitian deskriptif kuantitatif. Penelitian deskriptif kuantitatif maksudnya penelitian ini hanya ingin mendeskripsikan atau memaparkan situasi yang sedang berlangsung pada saat penelitian diadakan dan tidak bermaksud menguji hipotesis. Metode yang dilakukan dalam penelitian ini adalah metode survey dengan teknis tes dan pengukuran. Populasi penelitian ini adalah seluruh pemain putra bola voli setrak jaya Kabupaten Serdang Bedagai Tahun 2019/2020 yang berjumlah 16

Pemain .Sedangkan sampel penelitian ini adalah pemain bola voli putra yang mengikuti latihan bola voli yang berjumlah 16 pemain. Untuk mengukur keterampilan passing bawah bola voli pemain putra setrak jaya Kabupaten Serdang Bedagai tahun 2019/2020 menggunakan petunjuk Tes Keterampilan Bola voli dari Pusat Kesegaran Jasmani dan Rekreasi Departemen Pendidikan Nasional tahun 2009, petunjuk tes keterampilan Passing bawah bola voli.Hasil penelitian menunjukan bahwa keterampilan passing bawah bola voli putra setrak jaya Kabupaten Serdang Bedagai tahun 2019/2020, kemampuan passing bawah pemain putra setrak jaya Kabupaten Serdang Bedagai berada pada kategori "Cukup" karena sudah ada beberapa siswa yang dapat melakukan Passing dengan benar tetapi masih ada juga beberapa siswa yang masih melakukan kesalahan dalam melakukan passing, kesalahan-kesalahan siswa itu dalam melakukan passing ialah siswa belum mampu membuat bola menyebrangi net, karena posisi kaki saat passing bola tidak sesuai target. Hal ini dapat dilihat dari perhitungan data yang telah didapatkan sebagai berikut: ketegori "sangat kurang" sebesar 0\% (0 pemain ), kategori "kurang" sebesar 25\% (4 pemain ), kategori “cukup" sebesar 56,25\% (9 pemain ), kategori "baik" sebesar 18,75\% (3 pemain) "sangat baik" sebesar $0 \%$ (0 pemain)
\end{abstract}

Kata Kunci : Keterampilan passing bawah bola voli

\section{ABSTRACT}

This research is a descriptive quantitative research. Quantitative descriptive research means that this research only wants to describe or describe the situation that was ongoing at the time of the research and does not intend to test the hypothesis. The method used in this research is 
a survey method with technical tests and measurements. The population of this study were all male volleyball players setrak Jaya, Serdang Bedagai Regency in 2019/2020, totaling 16

Players. While the sample of this study were male volleyball players who took part in volleyball training, totaling 16 players. To measure the volleyball underpass skills of the male players in Serdang Bedagai Regency in 2019/2020 using the Volleyball Skills Test instructions from the Center for Physical Fitness and Recreation of the Ministry of National Education in 2009, instructions for the volleyball Passing skills test. The results showed that Under the men's volleyball hit hit Serdang Bedagai Regency in 2019/2020, the underpass ability of the male players hit the hit Serdang Bedagai Regency is in the "Enough" category because there are already several students who can pass correctly but there are also some students who are still doing errors in doing the passing, the students' mistakes in doing the passing are the students have not been able to make the ball cross the net, because the position of the feet when passing the ball is not on target. This can be seen from the calculation of the data that has been obtained as follows: the "very poor" category is $0 \%(0$ players), the "less" category is $25 \%$ (4 players), the "enough" category is $56.25 \%$ (9 players ), the "good" category was $18.75 \%$ (3 players) "very good" at $0 \%$ (0 players)

\section{Keywords: Volleyball passing skills}

\section{PENDAHULUAN}

Passing bawah merupakan salah satu teknik dasar bola voli yang paling mudah jika dibandingkan teknik lainnya. Namun tidak menutup kemungkinan bagi pemain sering melakukan kesalahan, sehingga kualitas passing bawah yang dihasilkan tidak sesuai yang diharapkan. Setiap individu mempunyai tingkatan teknik yang berbeda-beda dalam bermain voli. Ada yang baik ada pula yang kurang baik, dalam segi teknik banyak terlihat juga dalam diri setiap pemain putra bola voli setrak jaya Kabupaten Serdang Bedagai, misalnya keterampilan passing bawah.

Berdasarkan hasil observasi pendahuluan dan wawancara dengan pelatih pada hari senin, 16 Maret 2020 yang telah dilakukan di Lapangan bola voli setrak jaya Tahun 2019/2020, tentang keterampilan passing bawah bola voli putra setrak jaya, diketahui ada pemain yang terampil melakukan macam-macam bentuk passing bawah, namun ada juga pemain yang kurang terampil dalam melakukan passing bawah bola voli, hal ini dapat dilihat dari adanya beberapa kesalahan yang sering terjadi saat melakukan passing bawah dalam bola voli antara lain: Ketika menerima bola lengan terlalu tinggi, kemudian lanjutan lengan berada di atas bahu, tubuh terlalu rendah karena pinggang ditekuk sehingga operan terlalu rendah dan kencang seharusnya yang ditekuk adalah lutut dan lengan terpisah sesaat, sebelum, pada saat, atau sesaat sesudah menerima bola, serta bola mendarat di lengan daerah siku.

Keterampilan passing bawah bola voli putra setrak jaya Kabupaten Serdang Bedagai yang masih kurang terarah sehingga menyebabkan permainan voli kurang kelihatan menarik. Berdasarkan permasalahan yang terjadi di atas dapat ditarik kesimpulan bahwa penting untuk mengetahui seberapa besar keterampilan passing bawah bola voli dengan melakukan penelitian. Melalui tes keterampilan passing bawah bola voli diharapkan dapat mengetahui seberapa besar tingkat keterampilan bermain voli pada pemain bola voli putra setrak jaya Kabupaten Serdang Bedagai.

Benny Aprial. M, dan Ika Endah Puspita Sari dalam jurnal Of Nursing And Midwifery In the execution of the subject matter under the passing can not be fully conveyed properly suit the demands of the curriculum used in schools, curriculum unit level pendidikan.Terlihat of delivery of material that the teacher has not been conveyed systematically as in the phase of reasoning and communicating was not implemented in learning as well as the material does not fully accepted students about the material 
passing down because teachers do not provide feedback and reinforcement material provided on learning so that the learning outcomes of passing down less than the maximum. This can be seen when students perform below passing, movement which did still not correspond to the actual movement which includes the preparation phase, among which one of such a view do not look into the ball.

Sebagai pelatih untuk mengantisipasi hal tersebut maka harus pandai-pandai membuat inovasi latihan sebaik mungkin untuk dapat meningkatkan keterampilan passing bawah pemain . Dalam kegiatan latihan bola voli di lapangan setrak jaya, bermacam-macam bentuk kegiatan yang diberikan mulai dari kemampuan dasar, taktik, dan teknik bertanding bola voli yang sebenarnya. Agar dapat menguasai teknik dasar bermain bola voli diperlukan waktu yang cukup lama untuk berlatih. Masing-masing pemain membutuhkan waktu yang berbeda-beda dalam penguasaan suatu teknik dasar. Bakat, minat, dan kedisiplinan dalam berlatih sangat menetukan dalam penguasaan kemampuan dasar bermain bola voli. Pada saat kegiatan latihan berlangsung, lebih banyak fisik, sehingga latihan terkesan monoton. Latihan yang mengarah ke teknik, khususnya teknik passing bawah sangat jarang dilakukan,. Permasalahan yang terkait dengan latihan passing bawah bola voli sangat kompleks.

\section{METODE PENELITIAN}

Penelitian ini termasuk penelitian deskriptif kuantitatif. Penelitian deskriptif kuantitatif maksudnya penelitian ini hanya ingin mendeskripsikan atau memaparkan situasi yang sedang berlangsung pada saat penelitian diadakan dan tidak bermaksud menguji hipotesis. Metode yang dilakukan dalam penelitian ini adalah metode survey dengan teknis tes dan pengukuran. Untuk mengetahui data secara nyata digunakan tes kemampuan teknik dasar passing bawah bola voli. Unsur penilaian tes kterampilan passing bawah yang mengacu pada teknik dasar passing bawah bola voli oleh Depdiknas (1999:18).

Sampel adalah sebagian atau wakil dari populasi yang diteliti (Suharsimi Arikunto, 2006:104). Teknik pengambilan data sampel dalam penelitian ini dengan populasi putra setrak jaya Kabupaten Serdang Bedagai yang mengikuti latihan bola voli berjumlah 16 pemain , menggunakan total sampling. Artinya sampel yang digunakan sama dengan seluruh anggota yang terdapat dalam populasi tersebut atau dari semua jumlah pemain bola voli putra setrak jaya Kabupaten Serdang Bedagai yang mengikuti latihan bola voli dijadikan subyek penelitian secara keseluruhan (total). Jadi sampel penelitian ini adalah pemain bola voli putra setrak jaya Kabupaten Serdang Bedagai yang mengikuti latihan bola voli yang berjumlah 16 pemain .

\section{HASIL DAN PEMBAHASAN}

Penelitian ini bertujuan untuk mengetahui tingkat keterampilan passing bawah pemain yang mengikuti kegiatan latihan bola voli disetrak jaya Kabupaten Serdang Bedagai. Berdasarkan hasil analisis tersebut menunjukkan bahwa mayoritas pemain memiliki tingkat keterampilan passing bawah dalam kategori baik, yakni 3 
pemain $(18,75 \%)$ yang sudah memiliki keterampilan melakukan passing dalam kategori cukup ada 9 pemain $(56,25 \%)$, namun ada 4 pemain $\quad(25 \%)$ dalam kategori kurang, banyak pemain yang salah dalam melakukan teknik passing bawah. pemain tidak mengetahui teknik passing bawah yang baik dan benar, terutama pada sikap awalan dan perkenaan. Pada sikap awalan yang seharusnya posisi badan rendah, kaki ditekuk, akan tetapi banyak pemain yang masih dalam posisi tegap.

Pada sikap perkenaan kebanyakan perkenaan bola tidak tepat, sehingga hasil passing yang dilakukan tidak baik. Passing berarti mengumpan atau mengoper, teknik ini adalah teknik dasar yang cukup sulit dan digunakan dalam permainan bola voli. penguasaan passing bawah harus dikuasai oleh seorang pemain bola voli. Karena akan menentukan cara bermain dalam permainan bola voli, karena penerimaan passing yang baik adalah awal dari keberhasilan smash dan apabila passing baik maka permainan akan berjalan dengan baik juga.

Kesalahan maupun cara memperbaiki passing bawah harus diperhatikan oleh pelatih. Pada umumnya pemain tidak mampu mengamati letak kesalahan yang dilakukan. Seorang pelatih harus mampu mencermati setiap bentuk gerakan yang dilakukan anak didiknya, sehingga akan diketahui letak kesalahannya. Setiap kesalahan yang dilakukan, pelatih segera mungkin untuk membetulkan gerakan yang salah, sehingga kualitas passing bawah yang dilakukan hasilnya sesuai yang diharapkan.

Passing adalah usaha ataupun upaya seorang pemain bola voli dengan cara menggunakan suatu teknik tertentu yang tujuannya untuk mengoperkan bola yang dimainkannya itu kepada teman seregunya untuk dimainkan dilapangan sendiri. Dengan adanya passing yang baik maka dapat membuat serangan yang baik ke daerah lawan sehingga dapat menghasilkan skor.

Passing bawah merupakan teknik dasar bola voli. Teknik ini digunakan untuk menerima servis, menerima spike, memukul bola setinggi pinggang ke bawah dan memainkan bola yang memantul dari net. Passing bawah merupakan awal dari sebuah penyerangan dalam bola voli. Keberhasilan penyerangan tergantung dari baik buruknya passing bawah. Apabila bola yang dioperkan jelek, maka pengumpan akan mengalami kesulitan untuk menempatkan bola yang baik untuk para penyerang.

Implikasi penelitian ini adalah untuk bahan pertimbangan dalam latihan passing bawah bola voli Putra Setrak Jaya Kabupaten Serdang Bedagai, supaya dalam permainan bisa mencapai hasil yang maksimal. Perbaikan teknik passing bawah bola voli putra setrak jaya Kabupaten Serdang Bedagai di setrak jaya yaitu dengan 
menambah latihan teknik bola voli supaya semua pemain memiliki teknik yang bagus, khususnya passing bawah dan bisa bermain dengan maksimal.

Dalam latihan khususnya tehnik dasar keterampilan passing bawah bola voli pemain kebanyakan lebih tinggi pengetahuan dibandingkan dengan praktek. Sehingga pemain butuh latihan untuk melakukan passing bawah agar putra setrak jaya Kabupaten Serdang Bedagai bisa berprestasi dalam bidang olahraga khususnya permainan bola voli.

\section{KESIMPULAN}

Dari hasil analisis data, dekskripsi, pengujian hasil penelitian, dan pembahasan, dapat diambil kesimpulan, bahwa kemampuan passing bawah pemain bola voli putra di setrak jaya Kabupaten Serdang Bedagai berada pada kategori "Cukup" karena sudah ada beberapa pemain yang dapat melakukan Passing dengan benar tetapi masih ada juga beberapa pemain yang masih melakukan kesalahan dalam melakukan passing, kesalahan-kesalahan pemain itu dalam melakukan passing ialah pemain belum mampu membuat bola menyebrangi net, karena posisi kaki saat passing bola tidak sesuai target. Hal ini dapat dilihat dari perhitungan data yang telah didapatkan sebagai berikut: ketegori "sangat kurang" sebesar 0\% (0 Pemain , kategori "kurang" sebesar 25\% (4 pemain ), kategori "cukup" sebesar 56,25\% (9 pemain ), kategori "baik" sebesar 18,75\% (3 pemain), "sangat baik" sebesar $0 \%$ (0 pemain)..

\section{DAFTAR PUSTAKA}

Depdiknas. 2009. Petunjuk Tes Keterampilan Bolavoli Usia $13-15$ Tahun. Jakarta: Pusat Kesegaran Jasmani dan Rekreasi Departemen Pendidikan NasionalSeri Pendidikan, Volume 3 Nomor 2.

Durrwachter G. 2015. Bola Voli Belajar dan Berlatih Sambil Bermain. Jakarta: Gramedia

M Aprial, Benny dan Ika Endah Puspitasari (2019) Efforts to Improve Learning Outcomes passing Down Volleyball Variations Through Learning and Modified Ball On Private Junior High School eighth grade students Perbaungan Satria Dharma School Year 2019/2020. In: Journal Of Nursing And Midwifery Vol 2, No. 1 December 2019.

Herry Koesyanto. 2016. Belajar Bermain Bola Volley. Semarang: FIK UNNES.

Nuril Ahmadi. 2017. Panduan Olahraga Bola Voli. Solo: Era Pustaka Utama. 